\title{
Genetic variations of ISLI associated with human congenital heart disease in Chinese Han people
}

Z.L. Luo ${ }^{1}$, H. Sun ${ }^{2}$, Z.Q. Yang ${ }^{2}$, Y.H. $\mathrm{Ma}^{3}$, Y. Gu${ }^{1}$, Y.Q. $\mathrm{He}^{2}$, D. Wei ${ }^{4}$ L.B. Xia ${ }^{4}$ B.H. Yang ${ }^{1}$ and T. Guo ${ }^{1}$

${ }^{1}$ Department of Cardiology,

The First Affiliated Hospital of Kunming Medical University, Kunming, Yunnan, China

${ }^{2}$ Department of Medical Genetics, Institute of Medical Biology,

Chinese Academy of Medical Sciences \& Peking Union Medical College, Kunming, Yunnan, China

${ }^{3}$ Department of Obstetrics and Gynecology,

The First Affiliated Hospital of Kunming Medical University, Kunming, Yunnan, China

${ }^{4}$ Department of Hepatobiliary Surgery,

The Second Affiliated Hospital of Kunming Medical University, Kunming, Yunnan, China

Corresponding author: T. Guo

E-mail: luozhiling126@126.com

Genet. Mol. Res. 13 (1): 1329-1338 (2014)

Received January 2, 2013

Accepted May 23, 2013

Published February 28, 2014

DOI http://dx.doi.org/10.4238/2014.February.28.5

ABSTRACT. Congenital heart disease (CHD) is the most common birth abnormality, but the etiology of CHD is unknown. ISL1 may play a fundamental role in cardiac morphogenesis, and mutations of this gene could cause CHD. To evaluate whether genetic variations of ISLI are associated with CHD in Chinese Han people, polymerase chain reaction restriction fragment-length polymorphism and $\mathrm{SNaPshot}$ were used to examine 9 polymorphisms of ISL1 in 233 patients with CHD 
as well as 288 healthy controls. We found that one SNP (rs1017) in ISL1 was significantly associated with simple CHD. Genetic variation of ISL1 was confirmed to be associated with the risk of CHD. ISLI is related to the atrial septal defect group and the ventricular septal defect group, and the genotypes were associated with the occurrence of CHD in the dominant mode of inheritance. We concluded that rs 1017 contributed to the risk of CHD in Chinese Han people, and ISLI may be involved in the formation and development of the heart.

Key words: Congenital heart disease; ISL1; Chinese Han people; rs1017

\section{INTRODUCTION}

Congenital heart disease (CHD) is a common cause of perinatal morbidity and mortality, affecting 1 in 20 live births, 1 in 100 of which require intervention (Pell, 2012). CHD is the main cause of death in infant noninfectious disease (Klink et al., 2012). CHD can be classified as simple CHD and non-syndrome CHD based on whether the heart associated with external cardiac abnormalities. In non-syndrome CHD, there is only a heart defect and no external cardiac abnormalities. The most common types of non-syndrome CHD are atrial septal defect and ventricular septal defect (Winkleby et al., 2007; de Goede et al., 2012; Oude et al., 2012).

Most scholars believe that embryonic genetic factors and environmental factors lead to abnormal development of the heart and blood vessels in $85 \%$ of CHD patients, and genetic factors are the most important. The incidence of CHD is relevant to chromosomal abnormalities, gene copy number abnormalities, single-gene mutations, and multi-gene mutations (Winkleby et al., 2007; de Goede et al., 2012; Misra et al., 2012; Morales et al., 2012; Oude et al., 2012).

The heart is one of the earliest formed organs during embryonic development, and the heart is divided into the first heart area and the second heart area. The second heart area is where cells differentiate into a complex organ morphology and the main area in which cardiac progenitor cells are formed and where the transcription factor ISL1 is produced.

The ISLI gene was first reported to control various aspects of motoneuron identity in early embryogenesis (Liang et al., 2011). ISL1 is widely expressed in cell lineages during embryogenesis (Bu et al., 2009; Kang et al., 2009; Liang et al., 2011) and can be isolated from postnatal hearts of rodents and humans that maintain the ability to differentiate into multiple cardiac lineages (Laugwitz et al., 2005; Moretti et al., 2006). Although mice deficient in ISL1 harbor defects in cardiac morphogenesis, the role of ISL1 in human CHD is unknown (Ahlgren et al., 1997; Cai et al., 2003; Stevens et al., 2010).

Some scholars found that mouse lacking ISLI formed heart teratogenesis. In addition, CHD and 9 single nucleotide polymorphisms (SNPs) of ISLI were significantly associated. However, few reports have described the relationship between CHD and gene polymorphisms in Chinese Han people (Xue et al., 2012; Zhao et al., 2012).

The main purpose of this study was to detect the distribution and frequency of 9 SNPs in the ISLI gene in Chinese Han people and to investigate the correlation between these SNPs and the most common non-syndrome CHDs, atrial septal defect and ventricular septal defect. 


\section{MATERIAL AND METHODS}

\section{Patients}

A cohort of 233 consecutive patients (102 male and 131 female cases with an average age of $22.9 \pm 16.8$ years), selected based on imaging evidence of CHD, were recruited from The First Affiliated Hospital of Kunming Medical University. There were 128 cases of atrial septal defect, 82 cases of ventricular septal defect, 12 cases of atrial septal defect with ventricular septal defect, 2 cases of atrial septal defect with persistent left superior vena, 1 case of atrial septal defect with patent ductus arteriosus, 1 case of atrial septal defect with mitral valve replacement, 1 case of atrial septal defect with aortic sinus of valsalva rupture, 2 cases of ventricular septal defect with patent ductus arteriosus, and 4 cases of ventricular septal defect with patent foramen ovale. CHD in all patients were confirmed by surgery. The baseline characteristics of the study patients $(\mathrm{N}=233)$ are reported in Table 1 . The 288 controls $(157$ male and 132 female cases with an average age of $39.6 \pm 9.9$ years) were screened by counselors who evaluated the patient history for absence of structural heart disease. Written informed consents were signed, and this study was approved by the Institutional Review Boards of Kunming Medical University. CHD patients and controls were all unrelated and of the Chinese Han people.

\begin{tabular}{lcr} 
Table 1. Distribution of congenital heart disease in the patients studied. & $\%$ \\
\hline Congenital heart disease (CHD) & N (total of 233) & 35.1 \\
\hline VSD & 82 & 0.8 \\
VSD + PDA & 2 & 1.7 \\
VSD + PFO & 4 & 5.2 \\
ASD + VSD & 128 \\
ASD & 2 & 54.9 \\
ASD + PLSV & 1 & 0.43 \\
ASD + PDA & 1 & 0.43 \\
ASD + Replacement of mitral valve & 1 & 0.43 \\
ASD + Ruptured aortic sinus aneurysm & 0.43 \\
\hline
\end{tabular}

$\mathrm{VSD}=$ ventricular septal defect; $\mathrm{PDA}=$ patent ductus arteriosus; $\mathrm{PFO}=$ patent foramen ovale; $\mathrm{ASD}=$ atrial septal defect; PLSV = permanent left superior vena cava.

\section{DNA extraction}

Five milliliters of peripheral blood was collected of the 233 patients and 288 healthy controls. The AxyPrep Blood Genomic DNA Miniprep Kit (Axygen, HangZhou, China) was used to extract DNA.

\section{Primer design and genotyping}

Nine SNPs were selected to examine the association between ISL1 and CHD. These SNPs have high heterozygosity in Chinese Han people based on Hapmap data (Phase II + III, rel 27). Four of these SNPs (rs6867206, rs6869844, rs3762977, and rs1017) were genotyped by polymerase chain reaction-restriction fragment length polymorphism (PCR-RFLP), and the other 5 SNPs (rs6449612, rs4865656, rs2115322, rs6449600, and rs150104955) were genotyped using SNaPshot. Primer 3.0 was used to design primers for PCR-RFLP genotyping, and Primer 5 
was used for SNaPshot genotyping. ISL1-specific gene primers were synthesized by Shang Hai Jierui Biological Engineering Co. Primers and their characteristics are listed in Table 2.

\begin{tabular}{|c|c|c|c|c|c|}
\hline Locus & Primers & $\begin{array}{c}\text { Product } \\
\text { (bp) }\end{array}$ & $\begin{array}{c}\text { Annealing } \\
\text { temperature }\left({ }^{\circ} \mathrm{C}\right)\end{array}$ & $\begin{array}{l}\text { Restriction } \\
\text { endonuclease }\end{array}$ & $\begin{array}{l}\text { Fragment size after digestion/ } \\
\text { Extended primers/Length of the } \\
\text { extended primer }\end{array}$ \\
\hline rs6867206 & $\begin{array}{l}\text { Forward primer: ACTGCTGCAAAATTCCAACC } \\
\text { Reverse primer: AGAGGGCCCATAGGTCTGAT }\end{array}$ & 296 & 60 & SSiI & $\begin{array}{l}\text { CT }(296 / 216 / 80), \text { CC }(216 / 80) \text {, } \\
\text { TT (296) }\end{array}$ \\
\hline rs6869844 & $\begin{array}{l}\text { Forward primer: GCATCCAAATTCTCCCCATA } \\
\text { Reverse primer: AGATGCCACAGAACATGCAG }\end{array}$ & 375 & 60 & SSiI & $\begin{array}{l}\text { CT }(231 / 155 / 76), \text { CC }(155 / 76) \text {, } \\
\text { TT }(231)\end{array}$ \\
\hline rs3762977 & $\begin{array}{l}\text { Forward primer: GGGACCTCGTCAACAGGTAG } \\
\text { Reverse primer: GGCGCAGCTGTTCTGATTAT }\end{array}$ & 370 & 60 & SmaI & $\begin{array}{l}\mathrm{AG}(370 / 235 / 135), \mathrm{AA}(370) \\
\mathrm{GG}(235 / 135)\end{array}$ \\
\hline rs1017 & $\begin{array}{l}\text { Forward primer: CTCTTGGCCTGTCCTGTAGC } \\
\text { Reverse primer: GCAATGCAAGAGCAAACAAA }\end{array}$ & 318 & 60 & DraI & $\begin{array}{l}\text { AT (201/117/95/22), AA (201/117), } \\
\text { TT (201/95/22) }\end{array}$ \\
\hline rs6449612 & $\begin{array}{l}\text { Forward primer: GCATACTATAATGAAGGCACGG } \\
\text { Reverse primer: TTGAGCATTCGCCACCTTTTC } \\
\text { TTTTTCACCTCCTCAAAGAAGCATT }(25)\end{array}$ & 128 & 60 & & $\mathrm{C} / \mathrm{T}$ \\
\hline rs4865656 & $\begin{array}{l}\text { Forward primer: ACCTTTGGAGTGTGTTGTGTC } \\
\text { Reverse primer: TTCTTTCAGAGTACCTTAGGG } \\
\text { TTTTTTTTTTAGGGGAATTTTAAGACTCAA (30) }\end{array}$ & 127 & 60 & & $\mathrm{~A} / \mathrm{G}$ \\
\hline rs2115322 & $\begin{array}{l}\text { Forward primer: GACAAGTAGTCTCTGACCAAC } \\
\text { Reverse primer: GGCTTGACTAGGCAAAGAATC } \\
\text { TTTTTTTTTTAATGAATTCTTCCAACAATCC (32) }\end{array}$ & 130 & 60 & & $\mathrm{~A} / \mathrm{G}$ \\
\hline rs6449600 & $\begin{array}{l}\text { Forward primer: AAGTAAGGCTAGGAAGCTCTG } \\
\text { Reverse primer: TATTCTGATGCCTAGGACTCC } \\
\text { TTTTTTTTTTTTTTAGAAAATTCTTGCTAA } \\
\text { TTCAC (37) }\end{array}$ & 131 & 60 & & $\mathrm{C} / \mathrm{T}$ \\
\hline rs150104955 & $\begin{array}{l}\text { Forward primer: TGGGAGACATGGGAGATCCAC } \\
\text { Reverse primer: GCAATGACTCCAACTCCAAAG } \\
\text { TTTTTTTTTTTTTTTTTTCAGCACACCGAG } \\
\text { CCCCACAAG }(40)\end{array}$ & 135 & 60 & & $\mathrm{C} / \mathrm{T}$ \\
\hline
\end{tabular}

PCR was performed to amplify rs6867206, rs6869844, rs3762977, and rs1017 using the following conditions: $20 \mathrm{ng}$ DNA sample, $1.2 \mu \mathrm{L} \mathrm{MgCl}_{2}(25 \mathrm{mM}), 1.6 \mu \mathrm{L} \mathrm{dNTP}(2.5 \mathrm{mM})$, $1 \mu \mathrm{L}$ forward and reverse primers $(5 \mu \mathrm{M}$ each $), 0.16 \mu \mathrm{L}$ Taq polymerase $(55 \mathrm{U} / \mu \mathrm{L}), 2 \mu \mathrm{L} 10 \mathrm{X}$ PCR buffer, and water to a total volume of $20 \mu \mathrm{L}$. The amplification conditions were as follows: 30 cycles at $94^{\circ} \mathrm{C}$ for $15 \mathrm{~s}, 60^{\circ} \mathrm{C}$ for $30 \mathrm{~s}, 72^{\circ} \mathrm{C}$ for $15 \mathrm{~s}$, and a final extension at $72^{\circ} \mathrm{C}$ for $10 \mathrm{~min}$. PCR reagents were purchased from TaKaRa.

PCR product $(5 \mu \mathrm{L})$, digestion buffer $(2 \mu \mathrm{L})$, and HhaI endonuclease $(1 \mathrm{U} / \mu \mathrm{L})(0.5 \mu \mathrm{L})$ (TakaRa, China) were diluted in nuclease-free water to a total volume of $20 \mu \mathrm{L}$ and digested at $37^{\circ} \mathrm{C}$ overnight. Finally, the results were identified with $2 \%$ agarose gel electrophoresis.

Genotypes of the 5 SNPs of ISL1 (rs6449612, rs4865656, rs2115322, rs6449600, and rs150104955) were determined using SNaPshot sequencing. PCR amplification were performed for these sites, and the amplification systems were as follows: $1 \mu \mathrm{L}$ DNA sample, $1.5 \mu \mathrm{L} \mathrm{MgCl}_{2}(25 \mathrm{mM}), 0.3 \mu \mathrm{L}$ dNTP, $0.15 \mu \mathrm{L}$ primer mixture $(20 \mathrm{p}), 0.3 \mu \mathrm{L}$ Taq polymerase $(55 \mathrm{U} / \mu \mathrm{L})$, and $1.5 \mu \mathrm{L} 10 \mathrm{X}$ PCR buffer diluted in nuclease-free water to a total volume of 15 $\mu \mathrm{L}$. The following standardized cycling conditions were applied: $95^{\circ} \mathrm{C}$ for $3 \mathrm{~min} ; 11$ cycles at $94^{\circ} \mathrm{C}$ for $15 \mathrm{~s}, 60^{\circ} \mathrm{C}$ for $15 \mathrm{~s}$, and $72^{\circ} \mathrm{C}$ for $30 \mathrm{~s} ; 24$ cycles at $94^{\circ} \mathrm{C}$ for $15 \mathrm{~s}, 54^{\circ} \mathrm{C}$ for 15 $\mathrm{s}, 72^{\circ} \mathrm{C}$ for $15 \mathrm{~s}$, and $72^{\circ} \mathrm{C}$ for $30 \mathrm{~min} ; 72^{\circ} \mathrm{C}$ for $30 \mathrm{~min}$. Three microliters of amplified PCR products was digested with ExoI and Sap as follows: $3 \mu \mathrm{L}$ PCR product, $0.2 \mu \mathrm{L}$ ExoI, 0.2 $\mu \mathrm{L}$ Sap, and $0.7 \mu \mathrm{L}$ ExoI buffer diluted in nuclease-free water to a total volume of $7 \mu \mathrm{L}$. The purification conditions were as follows: $37^{\circ} \mathrm{C}$ for $45 \mathrm{~min}$ and $80^{\circ} \mathrm{C}$ for $15 \mathrm{~min}$, and the 
extension reaction was performed after the purification. The extension reaction conditions were as follows: $2 \mu \mathrm{L}$ PCR product, $1 \mu \mathrm{L}$ Snapshot Mix, and $2 \mu \mathrm{L}$ extension primer mix diluted in water to a total volume of $6 \mu \mathrm{L}$. The conditions of the extension reaction were as follows: 30 cycles at $96^{\circ} \mathrm{C}$ for $10 \mathrm{~s}, 52^{\circ} \mathrm{C}$ for $5 \mathrm{~s}$, and $60^{\circ} \mathrm{C}$ for $30 \mathrm{~s}$. One microliter of extension product was removed from the sample ( $8 \mu \mathrm{L}$ total sample), denatured at $95^{\circ} \mathrm{C}$ for $3 \mathrm{~min}$, and analyzed using an ABI 3730XL sequencer. The data were processed by GeneMapper 4.0 (Applied Biosystems, USA).

\section{Statistical methods}

Individual SNPs were analyzed using the chi-square test in the SPSS version 13 software (Chicago, IL, USA). Significance testing was adjusted for multiple comparisons with the Bonferroni correction, and the $95 \% \mathrm{CI}$ was calculated. Pairwise linkage disequilibrium analysis was performed using 3 SNP pairs. We used D' values and $\mathrm{r}^{2}$ values $>0.8$ to assign SNP locations to one haplotype block. SNPs with an $\mathrm{r}^{2}$ value $<0.5$ were selected as tagged, and Bonferroni corrections were made. Hardy-Weinberg tests were performed for all SNPs.

\section{RESULTS}

\section{Allele frequency}

\section{PCR-RFLP method for genotyping}

The PCR-amplified fragment length of the rs3762977 locus was $370 \mathrm{bp}$. After digestion, the AA allele appeared at $370 \mathrm{bp}$, the GG allele appeared at 235 and $135 \mathrm{bp}$, and the AG genotype appeared at 370, 235, and $135 \mathrm{bp}$. The PCR-amplified fragment length of the rS1017 locus was $318 \mathrm{bp}$. After digestion, the AA allele-type map appeared as 201- and 117-bp fragments, the TT allele type appeared as 201-, 95-, and 22-bp fragments, and the AG genotype appeared as 201-, 117-, 95-, and 22-bp fragments.

\section{SNaPshot method for genotyping}

Sequencing results for the rs6449612, rs4865656, rs2115322, rs6449600, and rs150104955 loci are shown in Figure 1. Green represents the A allele, blue the G allele, black the $\mathrm{C}$ allele, and red the $\mathrm{T}$ allele. The genotyping results were heterozygous for bimodal and homozygous for wild-type; mutant homozygotes were single peaks.

\section{Results of the statistical analysis}

All SNPs of the cases and controls are in line with the genetic balance Hardy-Weinberg test. Allele frequencies were obtained from simple counting. The most common types of CHD were atrial septal and ventricular septal defects. Meanwhile, we analyzed 2 subgroup components of CHD, atrial septal defect, and ventricular septal defect, respectively. We found that these are in line with CHD, the atrial septal defect group, and the ventricular septal defect group. The $\mathrm{T}$ gene frequency of the rs 1017 locus was statistically different, and we discuss 
a genetic model for T. If T was seen as a "disease allele", the AT and TT genotype phenotypes were consistent in the dominant inheritance pattern, while the AA genotype phenotype with AT or TT phenotypes were opposite. We are unable to make a recessive genetic pattern analysis, because the TT genotype in the control group was not found. According to the gene frequency and the assumed genetic model, the chi-square test was performed in the locus allele and genotype of the CHD group, atrial septal defect group, and ventricular septal defect group but not in the control group. The rs 1017 alleles were associated with the incidence of CHD in all groups $(\mathrm{P}=0.000037)$, and the genotype was associated with the incidence of CHD in the dominant mode of inheritance $(\mathrm{P}=0.0005)$ and was related to the atrial septal defect group and ventricular septal defect group (ASD: $\mathrm{P}=0.00017$; VSD: $\mathrm{P}=0.00041$ ). The genotypes were associated with the occurrence of CHD in the dominant mode of inheritance (ASD: $\mathrm{P}=$ 0.0021; VSD: $\mathrm{P}=0.0075)$. Details are listed in Tables 3 and 4.

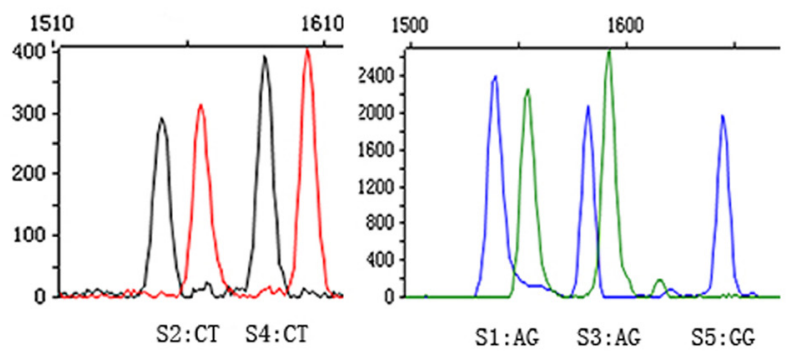

Figure 1. SNaPshot sequencing diagram of 5 SNPs in the ISL1 gene. S1: rs6449612, S2: rs4865656, S3: rs2115322, S4: rs6449600, S5: rs150104955. (A: green, G: blue, C: black, T: red).

Table 3. Allele frequency of the ISLI gene in congenital heart disease and normal control groups.

\begin{tabular}{|c|c|c|c|c|c|c|c|}
\hline \multirow[t]{2}{*}{ Allele/Genotype } & \multirow{2}{*}{$\begin{array}{c}\text { Controls } \\
{[\mathrm{N}=288 \text { (Freq.)] }}\end{array}$} & \multicolumn{2}{|l|}{ Cases } & \multicolumn{2}{|l|}{ VSD } & \multicolumn{2}{|l|}{ ASD } \\
\hline & & {$[\mathrm{N}=233$ (Freq.) $]$} & $P$ value & [N = 82 (Freq.)] & $P$ value & {$[\mathrm{N}=128$ (Freq.) $]$} & $P$ value \\
\hline \multicolumn{8}{|l|}{ rs6867206 } \\
\hline $\mathrm{T}$ & $515(0.894)$ & $403(0.865)$ & & $139(0.848)$ & & $37(0.134)$ & \\
\hline C & $61(0.106)$ & $63(0.135)$ & 0.1465 & $25(0.152)$ & 0.1009 & $219(0.866)$ & 0.1106 \\
\hline \multicolumn{8}{|l|}{ rs6869844 } \\
\hline $\mathrm{C}$ & $563(0.977)$ & $447(0.959)$ & & $154(0.939)$ & & $247(0.968)$ & \\
\hline $\mathrm{T}$ & $13(0.023)$ & $19(0.041)$ & 0.0903 & $10(0.061)$ & 0.0124 & $9(0.033)$ & 0.2963 \\
\hline \multicolumn{8}{|l|}{ rs3762977 } \\
\hline A & $551(0.957)$ & $453(0.972)$ & & $154(0.939)$ & & $273(0.989)$ & \\
\hline G & $25(0.043)$ & $13(0.028)$ & 0.1843 & $10(0.061)$ & 0.3496 & $3(0.011)$ & 0.01934 \\
\hline \multicolumn{8}{|l|}{ rs1017 } \\
\hline A & $536(0.931)$ & $397(0.852)$ & & $128(0.842)$ & & $217(0.848)$ & \\
\hline $\mathrm{T}$ & $40(0.069)$ & $69(0.148)$ & 0.000037 & $26(0.159)$ & 0.00041 & $39(0.152)$ & 0.00017 \\
\hline \multicolumn{8}{|l|}{ rs6449612 } \\
\hline $\mathrm{C}$ & $491(0.867)$ & $385(0.837)$ & & $135(0.823)$ & & $210(0.820)$ & \\
\hline $\mathrm{T}$ & $75(0.133)$ & $75(0.163)$ & 0.1528 & $29(0.177)$ & 0.1528 & $46(0.180)$ & 0.1976 \\
\hline \multicolumn{8}{|l|}{ rs 4865656} \\
\hline & $496(0.876)$ & $387(0.841)$ & & $135(0.823)$ & & $212(0.828)$ & \\
\hline A & $70(0.124)$ & $73(0.158)$ & 0.08001 & $29(0.177)$ & 0.0800 & $44(0.173)$ & 0.1748 \\
\hline \multicolumn{8}{|l|}{ rs2115322 } \\
\hline A & $491(0.867)$ & $386(0.839)$ & & $134(0.817)$ & & $213(0.321)$ & \\
\hline G & $75(0.133)$ & $74(0.161)$ & 0.199 & $30(0.183)$ & 0.1052 & $43(0.168)$ & 0.3962 \\
\hline \multicolumn{8}{|l|}{ rs6449600 } \\
\hline C & $547(0.966)$ & $448(0.974)$ & & $157(0.957)$ & & $247(0.965)$ & \\
\hline $\mathrm{T}$ & $19(0.034)$ & $12(0.026)$ & 0.486 & $7(0.043)$ & 0.5792 & $9(0.035)$ & 0.2828 \\
\hline \multicolumn{8}{|l|}{ rs150104955 } \\
\hline $\mathrm{C}$ & $566(1.000)$ & $460(1.000)$ & & $164(1.000)$ & & $256(1.000)$ & \\
\hline
\end{tabular}

$\mathrm{P}<0.006$ was taken as positive in the chi-square test via Bonferroni's correction. VSD $=$ ventricular septal defect group; ASD = atrial septal defect group. 
Table 4. Analysis of gene rs1017 allele distribution associated with congenital heart disease.

\begin{tabular}{|c|c|c|c|c|c|c|c|c|c|c|}
\hline \multirow[t]{2}{*}{ rs1017 } & \multirow{2}{*}{$\begin{array}{c}\text { Controls } \\
\mathrm{N}=288 \\
\text { (Freq) }\end{array}$} & \multicolumn{3}{|c|}{ Cases } & \multicolumn{3}{|c|}{ VSD } & \multicolumn{3}{|c|}{ ASD } \\
\hline & & $\begin{array}{c}\mathrm{N}=231 \\
\text { (Freq) }\end{array}$ & P value & $\overline{\mathrm{OR}}(95 \% \mathrm{CI})$ & $\begin{array}{l}\mathrm{N}=82 \\
\text { (Freq) }\end{array}$ & P value & OR $(95 \% \mathrm{CI})$ & $\begin{array}{l}\mathrm{N}=128 \\
\text { (Freq) }\end{array}$ & P value & OR $(95 \% \mathrm{CI})$ \\
\hline \multicolumn{11}{|l|}{ Dominant mode } \\
\hline $\mathrm{AT}+\mathrm{TT}$ danger & $40(0.139)$ & $61(0.262)$ & & & $24(25.8)$ & & & $36(26.1)$ & & \\
\hline AA & $248(0.861)$ & $172(0.738)$ & 0.0005 & $\begin{array}{c}2.199 \\
(1.411-3.427)\end{array}$ & $69(74.2)$ & 0.0075 & $\begin{array}{c}2.157 \\
(1.217-3.821)\end{array}$ & $102(73.9)$ & 0.0021 & $\begin{array}{c}2.188 \\
(1.319-3.629)\end{array}$ \\
\hline
\end{tabular}

$\mathrm{VSD}=$ ventricular septal defect group; ASD = atrial septal defect group.

\section{Haplotype and linkage disequilibrium analysis}

The Haploview 4.2.0.0 software was used for linkage disequilibrium analysis, and the linkage disequilibrium Figure (LD Figure) was constructed according to the distribution of the 8 sites (Figure 2). Only 3 SNPs (rs6449612, rs4865656, and rs2115322) of this section are closely linked ( $D^{\prime}$ and $\mathrm{r}^{2}>0.85$ ), and the 3 SNPs were not linked with the positive sites of rs 1017. The Phase 2.1 Software was used in this study for haplotype analysis of the 3 SNPs, and 2 haplotypes accounted for the majority (CGA and TAG). There was no significant difference in the distribution of the CHD and control groups when comparing the 2 haplotypes ( $\mathrm{P}>$ 0.05). Details are listed in Table 5.

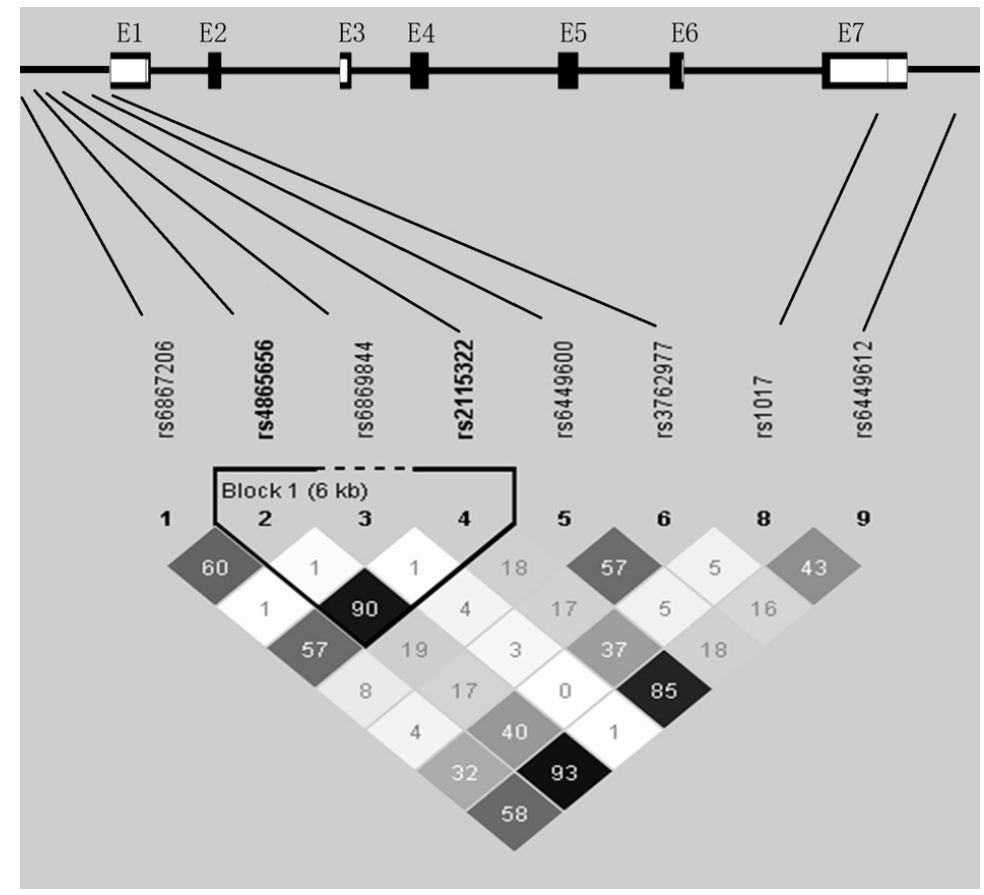

Figure 2. Linkage disequilibrium (LD) statistic $\left(\mathrm{r}^{2}\right)$ for the ISL1 gene. Genomic organization of the ISL1 gene, including the position of individual non-coding (open boxes) and coding (filled boxes) exons; the darker shading indicates stronger LD between SNPs. 
Table 5. Comparative analysis of the ISL1 haplotype in congenital heart disease and normal control groups.

\begin{tabular}{lccccc}
\hline Haplotypes & Cases (Freq.) & Controls (Freq.) & $\chi^{2}$ & Pearson P & Odds ratio (95\%CI) \\
\hline C G A & $381(0.828)$ & $486(0.859)$ & 1.99 & 0.158304 & $0.773(0.540-1.106)$ \\
T A G & $70(0.152)$ & $69(0.122)$ & 1.99 & 0.158304 & $1.294(0.904-1.852)$ \\
\hline
\end{tabular}

\section{DISCUSSION}

In the current study, 9 SNPs of the ISL1 gene in 233 patients with CHD were screened for genetic mutations. One SNP (rs1017) was found to be significantly associated with the risk of CHD in Chinese Han people.

CHD arises from abnormal heart development during embryogenesis (Wang et al., 2011; Misra et al., 2012; Zhao et al., 2012). The regulating morphogenesis of CHD has been extensively studied, confirming that some mutated genes, such as CATA4 and NK2.5, can cause CHD (Ng et al., 2011). However, these genes cannot explain all occurrences of CHD that have a genetic tendency through pathogenic gene mutations. The patients with gene mutations account for only a minority; therefore, it is still significant for revealing the etiology of CHD.

Some of the genes involved in the main forms of CHD have been identified. A new challenge is to identify the common causal polymorphisms of these genes.

ISL1 is a transcription factor-encoding gene that marks cardiac progenitor cells and controls secondary heart field differentiation, and new evidence suggests that purified populations of $I S L 1^{+}$progenitor cells are capable of self-renewal and expansion into cardiomyocyte, smooth muscle, and endothelial lineages (Ahlgren et al., 1997).

More than two-thirds of all heart cells, including cardiac pacemaker cells, vascular endothelial cells, vascular smooth muscle cells, and myocardial cell, are produced by $I S L 1^{+}$ heart precursor cells. In addition, normal expression of ISL1 is necessary for the proliferation, migration, and survival to myocardial precursor cells (Huang et al., 2012; Lee et al., 2012). In 2010, Steven et al. found 9 SNPs that cover the ISL1 gene and that are closely linked in European people. The allele types and haplotypes are closely related with the occurrence of CHD (Stevens et al., 2010) $(\mathrm{P}<0.001)$. Because the group difference has a large effect on the correlation with polygenic diseases, we studied the correlation between the 9 SNPs of the ISL1 gene as well as the occurrence of human non-syndrome CHD in the Chinese Han population.

Our results demonstrated that 1 ISL1 SNP was different (rs1017) and contributed to the risk of CHD in Chinese Han people. The data provided strong evidence that CHD is consistent with non-syndrome CHD in Chinese Han people $(\mathrm{P}=0.000037)$, and allele $\mathrm{T}$ is likely a risk factor for causing disease, consistent with what was found by Steven et al. When further exploring the genotype, we found that people with the AT or TT gene type of CHD are at higher risk than people with the AA genotype in the dominant model ( $\mathrm{OR}=2.329$, $95 \% \mathrm{CI}=1.545-3.511, \mathrm{P}=0.0005)$. A subgroup analysis of simple CHD was performed with the case group, and the results showed that rs 1017 was closely related to the incidence of the disease. Moreover, the occurrence of CHD patients with ASD or VSD who carried with AT or TT genotype was clearly higher than in people with the AA genotype in the dominant model (VSD: $\mathrm{OR}=2.157,95 \% \mathrm{CI}=1.217-3.821, \mathrm{P}=0.0075$; $\mathrm{ASD}$ : $\mathrm{OR}=2.188,95 \% \mathrm{CI}=1.319$ $3.629, \mathrm{P}=0.0021$ ). In this study, we only analyzed the dominant genetic model because there were no people with the TT genotype in the control group. We analyzed the haplotype linkage and found that there was no high-degree linkage at this region, and only 3 SNPs (rs6449612, 
rs4865656, and rs2115322) had a close linkage, but no linkage was found with rs1017, a disease risk site. In addition, there was no statistical significance to the analysis of the risk between the 2 main haplotypes (CGA and TAG) comprising the 3 SNPs.

Notably, recent research by Stevens et al. (2010) demonstrated that 2 different SNPs (rs1017 and rs3762977) of the ISL1 gene contribute to the risk of CHD in white and black/ African-American populations. Specifically, Stevens et al. showed that rs1017 significantly increased the risk of CHD in the white population, while no association was observed in the black/African-American population. Similarly, increased CHD risk was observed for rs3762977 in the black/African-American population but not in the white population. In contrast, rs3762977 was not found in sporadic CHD susceptibility in our study.

In addition to providing detailed and new insight into a variety of CHD phenotypes that can be produced from second heart field defects in humans, this study was designed to report the correlations between the ISLI gene and Chinese Han people with human CHD.

The rs 1017 SNP is located in the 3'-untranslated region of ISL1. We predicted the ISL1 3'-end interference (miRNA) binding site using the Targetscan software (Lewis et al., 2005) and found that rs 1017 and its surroundings did not possess an miRNA binding site. Therefore, we hypothesized that rs1017 has no influence on the function of the ISL1 gene. The reason why rs1017 shows a positive correlation with risk of disease in European whites and in our group is that it has linkage disequilibrium with the pathogenic gene. Stenven et al. (2010) found that rs 1017 has correlation with CHD in the European whites but not in the black or the African, which also supports our conclusion.

Further evidence that rs 1017 is a non-functional gene is the study performed by Xue et al. (2012) in the Chinese Han population of the Nan Jing area. This study focused on the distribution of rs1017 in normal individuals and patients with CHD. The study found that rs 1017 alone was not correlated with patients with CHD. This is not consistent with the results we observed in the Chinese Han population of the Yunnan area. Therefore, we assume that rs 1017 is not in linkage disequilibrium with the pathogenic mutation in the groups selected by Xue et al. (2012). Therefore, their statistical analysis may not have found the correlation. However, their research also confirmed that rs1017 is unlikely to change the function of ISL1. If rs 1017 can change the function of ISLI and lead to the occurrence of CHD, Xue et al. are unlikely to obtain a negative correlation.

In the Chinese population, we did not find that the ISL1 gene had strong linkage disequilibrium with the other SNPs in this report. However, the results of the positive correlation of rs1017 indicated that the gene is likely related with the incidence of CHD. To screen for a mutation that changes the function of ISL1, whole gene sequencing is required. Elucidating a mutation that changes the function is critical for elaborating the pathogenesis of CHD.

In conclusion, our study found that the Chinese Han population with CHD had ISLI gene mutations. Our observations may provide a foundation for a more integrated understanding of the molecular basis of human CHD. Further studies are required to discover and validate the risk factors of ISL1 SNP rs1017 in relation to CHD etiology.

\section{ACKNOWLEDGMENTS}

Research supported by the Yunnan Province Natural Science Foundation (grant \#2009ZC102M). 


\section{REFERENCES}

Ahlgren U, Pfaff SL, Jessell TM, Edlund T, et al. (1997). Independent requirement for ISL1 in formation of pancreatic mesenchyme and islet cells. Nature 385: 257-260.

Bu L, Jiang X, Martin-Puig S, Caron L, et al. (2009). Human ISL1 heart progenitors generate diverse multipotent cardiovascular cell lineages. Nature 460: 113-117.

Cai CL, Liang X, Shi Y, Chu PH, et al. (2003). Isl1 identifies a cardiac progenitor population that proliferates prior to differentiation and contributes a majority of cells to the heart. Dev. Cell 5: 877-889.

de Goede J, Geleijnse JM, Boer JM, Kromhout D, et al. (2012). Linoleic acid intake, plasma cholesterol and 10-year incidence of CHD in 20,000 middle-aged men and women in the Netherlands. Br. J. Nutr. 107: 1070-1076.

Huang ZP, Young SH, Zhou B, Chen J, et al. (2012). CIP, a cardiac Isl1-interacting protein, represses cardiomyocyte hypertrophy. Circ. Res. 110: 818-830.

Kang J, Nathan E, Xu SM, Tzahor E, et al. (2009). Is11 is a direct transcriptional target of Forkhead transcription factors in second-heart-field-derived mesoderm. Dev. Biol. 334: 513-522.

Klink T, Muller G, Weil J, Dodge-Khatami A, et al. (2012). Cardiovascular computed tomography angiography in newborns and infants with suspected congenital heart disease: retrospective evaluation of low-dose scan protocols. Clin. Imaging 36: 746-753.

Laugwitz KL, Moretti A, Lam J, Gruber P, et al. (2005). Postnatal isl1+ cardioblasts enter fully differentiated cardiomyocyte lineages. Nature 433: 647-653.

Lee S, Cuvillier JM, Lee B, Shen R, et al. (2012). Fusion protein Is11-Lhx3 specifies motor neuron fate by inducing motor neuron genes and concomitantly suppressing the interneuron programs. Proc. Natl. Acad. Sci. U. S. A. 109: 3383-3388.

Lewis BP, Burge CB and Bartel DP (2005). Conserved seed pairing, often flanked by adenosines, indicates that thousands of human genes are microRNA targets. Cell 120: 15-20.

Liang X, Song MR, Xu Z, Lanuza GM, et al. (2011). Isl1 is required for multiple aspects of motor neuron development. Mol. Cell Neurosci. 47: 215-222.

Misra C, Sachan N, McNally CR, Koenig SN, et al. (2012). Congenital heart disease-causing Gata4 mutation displays functional deficits in vivo. PLoS Genet. 8: e1002690.

Morales DL, Khan MS, Gottlieb EA, Krishnamurthy R, et al. (2012). Implantation of total artificial heart in congenital heart disease. Semin. Thorac. Cardiovasc. Surg. 24: 142-143.

Moretti A, Caron L, Nakano A, Lam JT, et al. (2006). Multipotent embryonic isl1+ progenitor cells lead to cardiac, smooth muscle, and endothelial cell diversification. Cell 127: 1151-1165.

$\mathrm{Ng} \mathrm{KM}$, Chan YC, Lee YK, Lai WH, et al. (2011). Cobalt chloride pretreatment promotes cardiac differentiation of human embryonic stem cells under atmospheric oxygen level. Cell Reprogram. 13: 527-537.

Oude Griep LM, Verschuren WM, Kromhout D, Ocke MC, et al. (2012). Variety in fruit and vegetable consumption and 10-year incidence of CHD and stroke. Public Health Nutr. 15: 2280-2286.

Pell JP (2012). Almanac 2012: cardiovascular risk scores. The National Society Journals present selected research that has driven recent advances in clinical cardiology. Hellenic J. Cardiol. 53: 412-419.

Stevens KN, Hakonarson H, Kim CE, Doevendans PA, et al. (2010). Common variation in ISL1 confers genetic susceptibility for human congenital heart disease. PLoS One 5: e10855.

Wang B, Zhou S, Chen Q, Xie X, et al. (2011). Hairy-related transcription factor 2 is not potentially related to congenital heart disease in Chinese patients. Int. J. Cardiol. 146: 415-416.

Winkleby M, Sundquist K and Cubbin C (2007). Inequities in CHD incidence and case fatality by neighborhood deprivation. Am. J. Prev. Med. 32: 97-106.

Xue L, Wang X, Xu J, Xu X, et al. (2012). ISL1 common variant rs1017 is not associated with susceptibility to congenital heart disease in a Chinese population. Genet. Test. Mol. Biomarkers 16: 679-683.

Zhao JY, Yang XY, Gong XH, Gu ZY, et al. (2012). Functional variant in methionine synthase reductase intron-1 significantly increases the risk of congenital heart disease in the Han Chinese population. Circulation 125: 482-490. 